\title{
NEW CDO ANNOUNCED
}

Following the retirement of Barry Cockcroft in February of this year, NHS England has announced that his successor will be Sara Hurley BDS(UBrist) MFGDP(UK) $\mathrm{MSc}(\mathrm{UCL}) \mathrm{MA}(\mathrm{KCL})$. Sara will serve as principal dental adviser and the professional head of dental staff in England. Sara will act as a senior member of the Medical Directorate, and work collaboratively to improve outcomes for patients, and champion the role of dentists and dentistry within the health system.

Sara Hurley qualified from the University of Bristol Dental School in 1988. Commissioned into the Royal Army Dental Corps, she has continued to broaden her clinical dentistry portfolio gaining Membership of General Dental Practitioners (UK) in 2003, a Masters in Dental Public Health at University College London 2004, and a King's College MA in Defence Studies 2007.

Her career has flexed across the domains of dental public health, wider healthcare policy and healthcare commissioning as well as undertaking operational healthcare management and strategic leadership assignments in a range of UK and overseas locations. She commented: "I am delighted and honoured to be taking up this new challenge as an integral member of the Medical Directorate at NHS England. The role of Chief Dental Officer remains a crucial link between decision-makers, patients and the wide range of front line providers that enable dental health. I am determined to use this position to articulate the dental health needs of our patients and, working collaboratively across the breadth of the dental healthcare profession, present directly to Ministers and NHS leaders our fresh ideas; ideas that will contribute to achieving our shared goals of quality health outcomes and better oral health for all."

Sara will now leave her post with the Royal Centre for Defence Medicine where she worked closely with the NHS in assuring access to, and quality of, healthcare for injured personnel. Concurrently, she also acted as the Chief Dental Officer for the Army and, in recognition of her work, was appointed as a Queen's Honorary Dental Surgeon in September 2014.

\section{BSPD WELCOMES BSDHT'S FIRST SMILES CAMPAIGN}

A campaign to introduce young children to oral health education in the classroom has been welcomed by the British Society of Paediatric Dentistry (BSPD) as an admirable initiative. The First Smiles campaign has been launched by the British Society of Dental Hygiene \& Therapy (BSDHT). Members of BSDHT are being encouraged to make contact with local schools and nurseries to organise a visit on 19 June to teach oral health in a fun and informative way. BSDHT is providing ideas and resources.

Claire Stevens, spokeswoman for BSPD, said: 'We know from recent surveys how important it is to ensure that all children have access to oral health advice, ideally at preschool age. BSPD would love visits such as these included as part of a nationwide programme of prevention. When combined with targeted measures for those in greatest need, we may finally be able to reduce the large number of children experiencing dental decay and the current inequalities in oral health. Until then, it's admirable that hygienists and therapists are taking the initiative and going into schools and nurseries to make oral hygiene fun.'

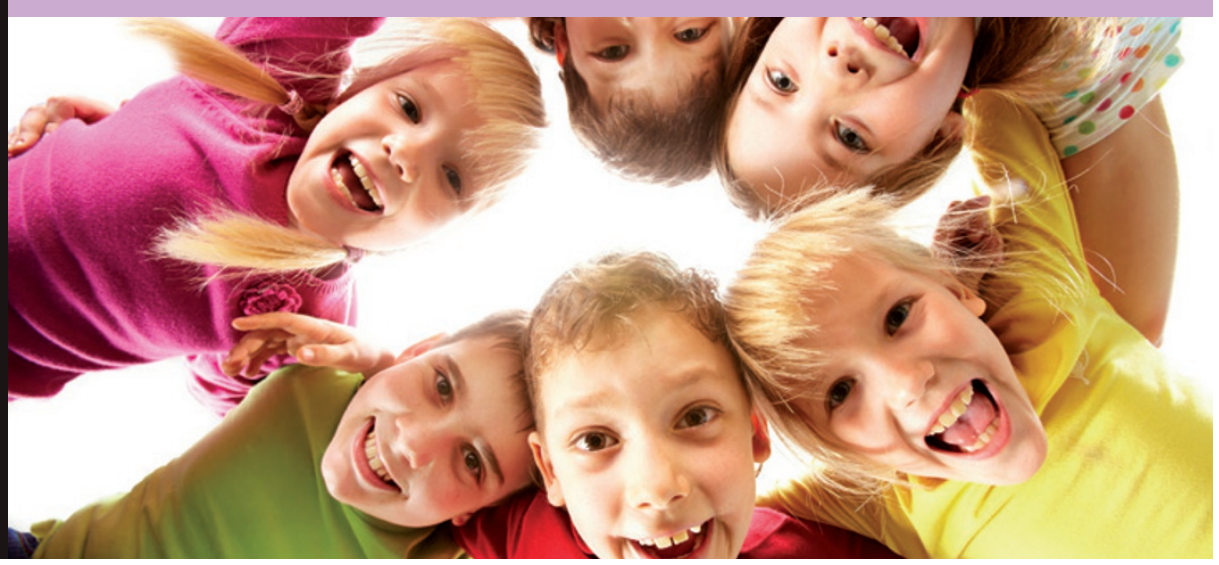

\section{1}

I

I

$$
1
$$

I

I

I

I

I
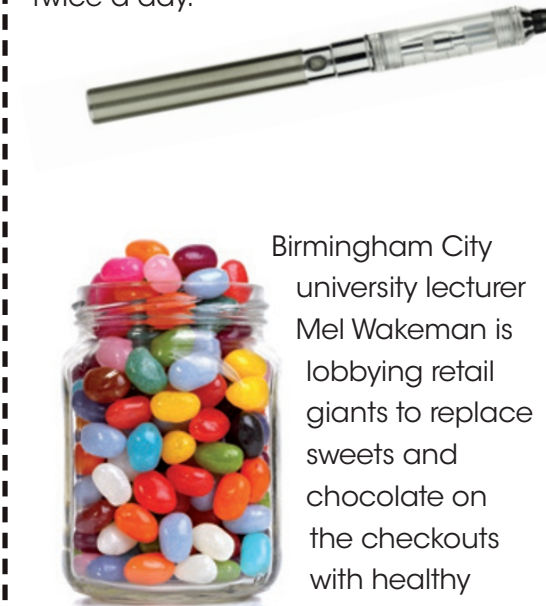

Birmingham City

university lecturer

Mel Wakeman is

lobbying retail

giants to replace

sweets and

chocolate on

the checkouts

with healthy

alternatives.

Cancer survivor David Billing, 48, has

- been given a new tongue made out

of part of his arm. Mr Billing had part

of his jaw and tongue removed after

- surgeons removed a tumour that

stopped him from swallowina.

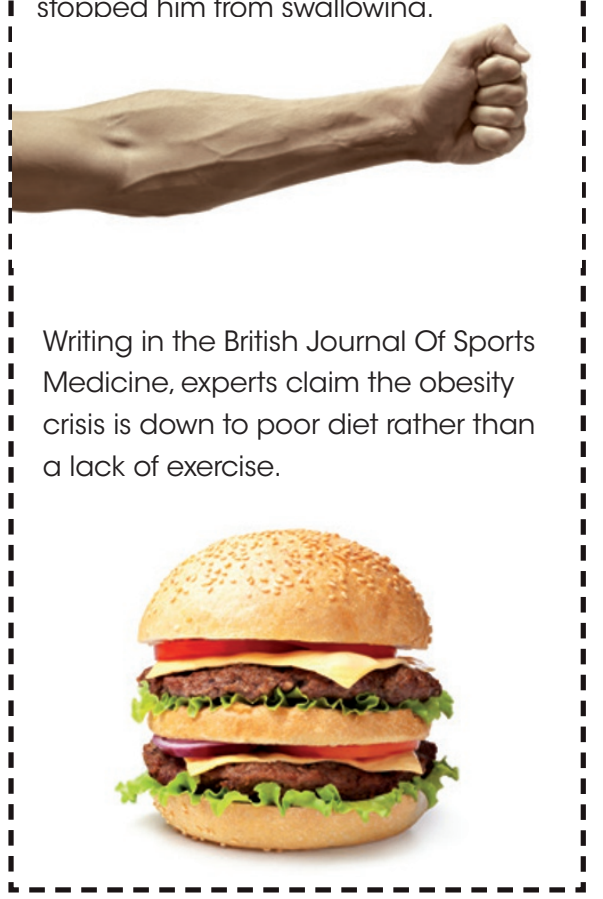

Do you have a news story that you

would like included in BDJ Team? Send

your press release or a summary of your

story to the Editor at

bdjteam@nature.com. 